\title{
Water Slide Injuries in Jamaica
}

\author{
C Fletcher, D McDowell
}

\begin{abstract}
Patients are presented in this study to describe injuries, each of which have not been previously described in the literature, as a result of a specific mechanism of injury on a water slide. Some of these injuries are potentially fatal and are usually the result of a very high energy mechanism of injury. All injuries occurred in a six-week time span in the summer of 2015. Injuries arising from water slides and their definitive treatments were documented. All of the cases presented to the St Ann's Bay Hospital in St Ann Jamaica. The mechanism of injury was analysed with a view to implement preventative measures. Three cases had, open book pelvic injuries and one of them also had a vaginal tear. All the open book injuries occurred after the patron's thighs violently abducted despite adhering to the recommended starting position which suggested that they crossed their legs. The fourth case is a 25-year old male who sustained a posterior shoulder dislocation as a result of his arms flailing despite attempting to adhere to the rule recommending that the patron should place his arms across the chest. The final case is a 14-year old male who was involved in an atypical collision injury which resulted in him receiving a displaced distal femoral fracture. Modern water slides will expose patrons to more frequent and severe injuries from atypical mechanism of injuries. Risk factors for injury must be factored into preventative measures. Improved surveillance strategies to monitor these injuries are suggested.
\end{abstract}

Keywords: Injuries, orthopaedic, water slide

\section{Lesiones en el tobogán de agua en Jamaica}

\author{
C Fletcher, D McDowell
}

\begin{abstract}
RESUMEN
En este estudio se presentan pacientes ara describir lesiones, cada una de las cuales no se han descrito previamente en la literatura, como resultado de un mecanismo específico de lesión en un tobogán de agua. Algunas de estas lesiones son potencialmente fatales y son generalmente el resultado de un mecanismo de muy alta energía de lesión. Todas las lesiones se produjeron en un período de seis semanas en el verano de 2015. Se documentan las lesiones producidas con los toboganes de agua, y se discuten los tratamientos definitivos. Todos los casos se presentaron al Hospital de la Bahía de St Ann, en St Ann, Jamaica. El mecanismo de lesión fue analizado con el fin de implementar medidas preventivas. Tres casos tenían lesiones pélvicas en libro abierto, y uno de ellos también tenía desgarro vaginal. Todas las lesiones en libro abierto ocurrieron después de una violenta abducción de los muslos del usuario, a pesar de adherirse a la posición inicial recomendada, según la cual debía mantener las piernas cruzadas. El cuarto caso es un varón de 25 años que sufrió una dislocación posterior del hombro como resultado de una sacudida de sus brazos, a pesar de intentar cumplir con la regla recomendada a los usuarios en cuanto a colocar sus brazos en el pecho. El último caso es un varón de 14 años que se vio involucrado en una lesión atípica de colisión, que dio lugar a una fractura desplazada del fémur distal. Los toboganes modernos exponen a los usuarios a lesiones más frecuentes y graves producidas por mecanismos de lesiones atípicos. Los factores de riesgo de lesiones deben ser incluidos como parte esencial de las me-
\end{abstract}

From: Department of Orthopaedics, St Ann’s Bay Regional Hospital, St Ann’s Bay, Jamaica.
Correspondence: Dr C Fletcher, 8 Doorly Boulevard, McCauley Heights, Kingston 6, St Andrew, Jamaica. 
didas preventivas. Se sugieren estrategias de vigilancia mejoradas para monitorear estas lesiones.lesiones.

Palabras claves: Lesiones, ortopedia, tobogán de agua

West Indian Med J 2016; 65 (3): 565

\section{INTRODUCTION}

Internationally, there has been a significant increase in water parks worldwide in the past two decades. Their introduction has been associated with increased numbers of traumatic cases involving different categories of injuries. Water park injuries may be divided into: water slides injuries, slips and falls on wet surfaces and swimming pool accidents (1). The potential for water slides injuries tends to be under-estimated by physicians and dentists until an outbreak occurs in a community (2). The focus in this case series is to describe injuries that have not previously been described secondary to a specific mechanism of injury from a water slides.

A variety of injuries occurring on a specific water slide at a popular water park in Jamaica were documented. All cases presented to the St Ann's Bay Regional Hospital in St Ann, Jamaica.

\section{CASE REPORTS}

\section{Case 1}

A 35-year old presented to our institution with anterior pelvic pain after descending on a thrill slide at a water park. He was assisted out of the water and was unable to weight-bear thereafter. Significant positive examination findings were, moderate painful distress, pubic tenderness and a mobile pelvis on compression. Vital signs were normal. X-rays demonstrated an eight centimeter pubic diastasis (Fig. 1). He was managed definitively with an external fixator (Fig. 2).

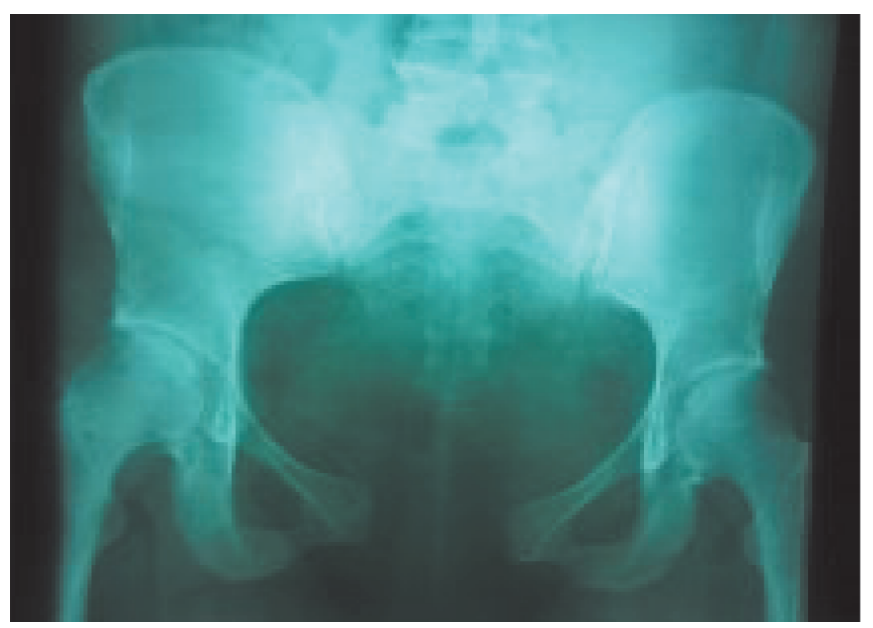

Fig. 1: Case 1: Anteroposterior pelvis injury film.

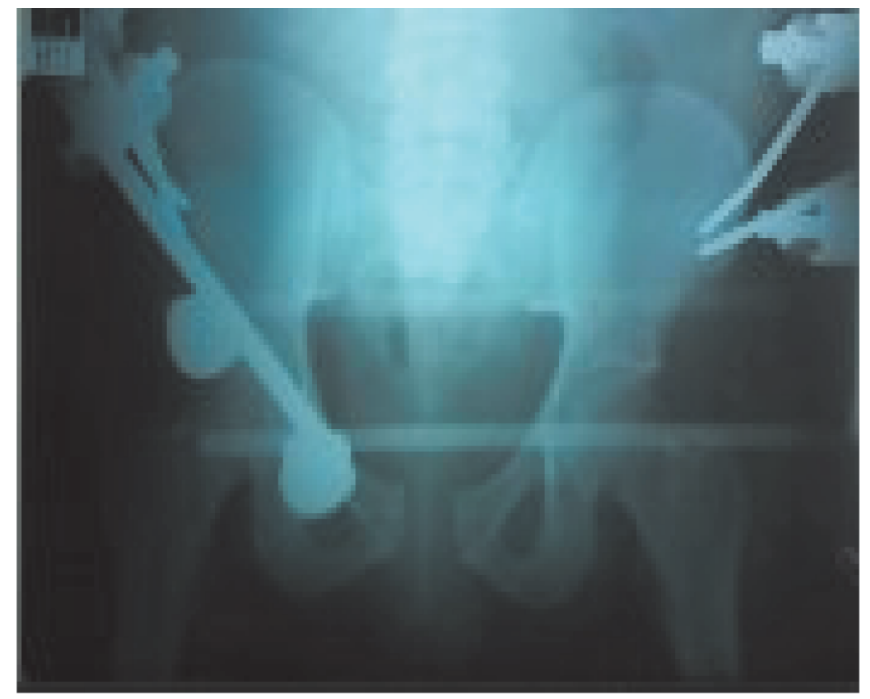

Fig. 2: Case 1 Post closed reduction and external fixation.

\section{Cases 2 and 3}

Two females: one 23 years old and one 37 years old, suffered the same open book injury with the same clinical features as the male patron but with one important exception; the 37-year old also presented with bleeding per vagina. The Gynaecology team diagnosed an associated vaginal laceration which had to be repaired emergently in the operating theatre. The 23-year old female was transferred to another institution for private care. The other female was managed definitively with open reduction and plate and screw fixation (Fig. 3).

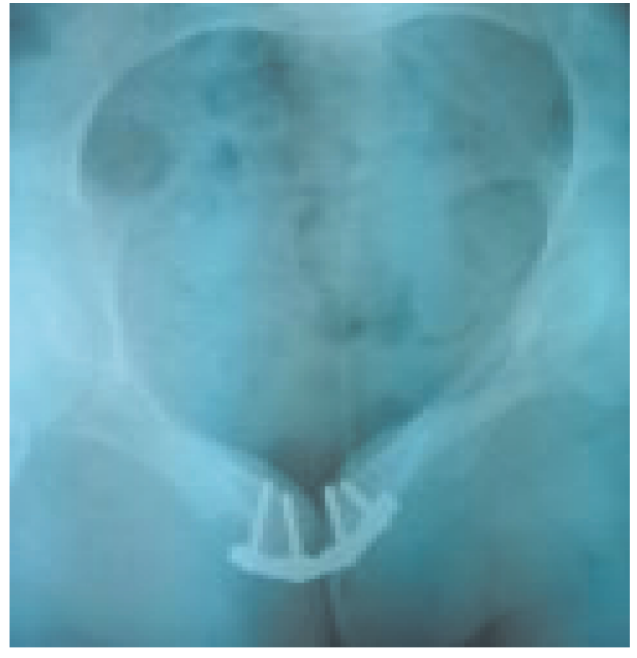

Fig. 3: Post open reduction and internal fixation. 
Case 4

A 25-year old male had significant flailing of his upper limbs during descent on the slide and complained of moderate left shoulder pain and an inability to move the shoulder. There was inability to externally rotate the arm actively or passively. X-rays confirmed a posterior shoulder dislocation (Fig. 4). He was emergently managed with closed reduction under conscious sedation in the emergency room.

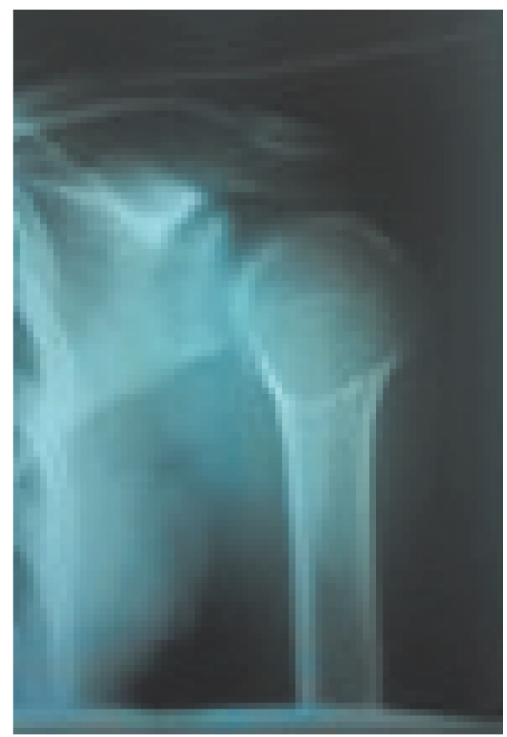

Fig. 4: Anteroposterior left shoulder injury film.

\section{Case 5}

A 14-year old male went down the slide uneventfully and then turned back to retrieve his goggles at the base of the slide. Another patron came down the slide at that time and collided with him. He had pain, swelling and deformity to the right-thigh. His relatives took him out of the water. X-rays revealed a completely displaced distal femoral Salter-Harris II physeal fracture (Fig. 5). He was definitively managed with closed reduction and K-wiring (Fig. 6).

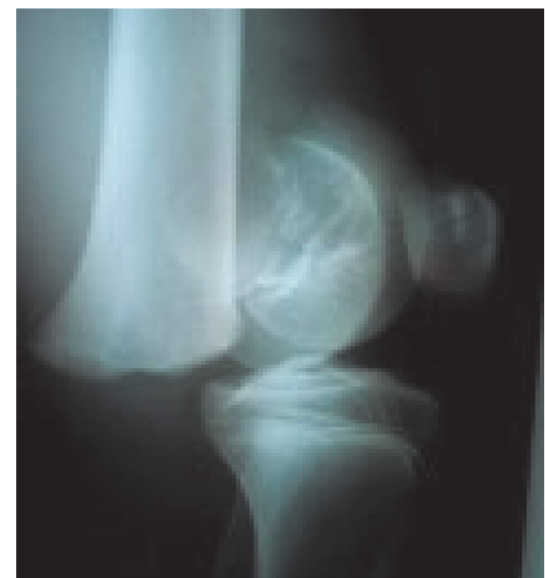

Fig. 5: Case 5 oblique right knee injury film.

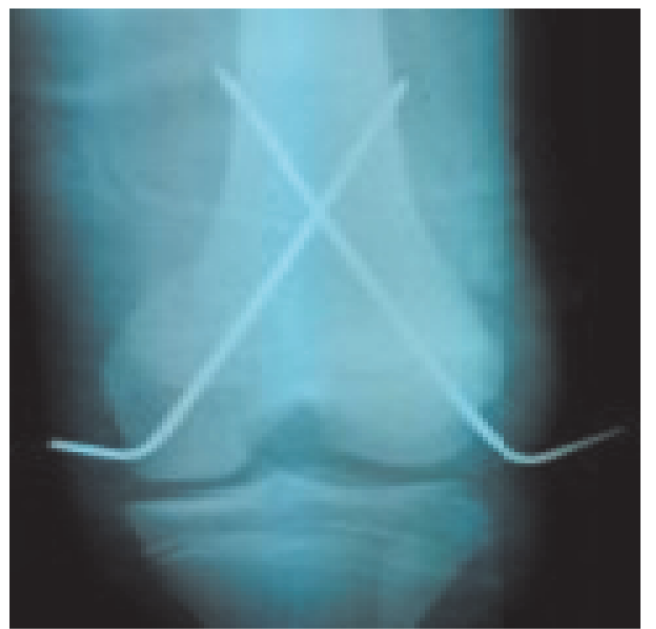

Fig. 6: Case 5 post closed reduction and K-wiring anteroposterior right knee.

At a particular point during descent, all of the patients described a 'thrill' as they accelerated suddenly. The sensation at the thrill point was that of hitting a bump on the slide which suddenly propelled them into the air which led them to unintentionally lose control of their limbs whereby the thighs violently abducted and the upper limbs flailed before hitting the water. Prior to going onto the slide, they were all instructed by park officials to place their arms across the chest and to cross their legs throughout descent until they hit the water. All of the above injuries took place in the span of six weeks.

\section{DISCUSSION}

A water slide is a stationary recreational device designed to provide descent on a flowing water film into a splash down body of water at the base of the slide. Approximately $86 \%$ of reported water park injuries involve water slides and are usually due to high velocity, on slippery slides (3). Exit velocities potentially may cause catastrophic injuries (4). The cases presented above, all occurred on the same slide at a popular amusement park which has six slides. It is the largest and highest velocity slide at the park. Its dimensions are 35 feet high and 120 feet long. Generally, a thrill ride has been defined as one which attempts to fool our brain into thinking that the body is in mortal danger which causes a considerable surge in adrenaline levels (3).

The literature on water slides is scant as well as outdated. This is especially significant considering that modern rides potentially expose patrons to more frequent and severe injuries (1). In a prospective observational study by Soyuncu et al (23), water slide injuries included: $26 \%$ head trauma (including 1 death), 26\% spinal injuries and 52\% were extremity injuries (1). Malpass et al (2), reported the following rates of waterslide injuries: sustained lacerations $(53 \%)$, contusions/abrasion $(25 \%)$, fractures $(7 \%)$, sprains $(7 \%)$, broken teeth $(6 \%)$ and concussions (3\%). Most injuries occurred in the head first position. The ratio of fibreglass slides to concrete slides was $12: 1$. 
A Washington amusement park reported that from July 13 to August 31, 65 persons sought medical care in local physicians' offices and emergency rooms (5). These cases were reported to the County Emergency Medical Service. The rate of injury recorded by the slide operators was 8.1 per 10000 rides, and the rate of medically treated injuries was 3.0 per 10000 (5). Patrons aged 5-14 years, 15-24 years and 25 years or older were fairly evenly distributed. The most common injuries were fractures, concussions, abrasions, sprains and strains. Most persons were aged 15 years or older for all injuries except concussions (5).

Detailed, constant computerized surveillance systems involving health centre's, private practices and all hospital emergency rooms are currently not in place in Jamaica, making completely accurate injury rates and hospital admission rates a challenge. The National Electronic Injury Surveillance System Accidents Records in the United States in 2006 recorded only one pelvic injury-a contusion (5). The majority of the lower limb injuries were strains and contusions.

The most common mechanism of injury in water slides involves hitting the floor of the pool or the opposite wall as a result of water entry at unfavourable speeds and/or position (1). Davis (6) described coming down a slide rapidly, aquaplaning and hitting the opposite wall to fracture his femur. Disobeying water park rules, for example, sliding head first and sliding immediately after the previous patron without an appropriate waiting period are the other possible injury mechanisms (1).

The literature did not have any data on risk factors for injuries until Paulozzi et al (1) study. He found that obesity and tandem riding were major risk factors. He postulated that the overweight individual was inactive with weak musculature leading to decreased control in their momentum. It was also noted that design changes in the slide subsequently resulted in fewer injuries (3). Of note, our patient with the open book injury and vaginal laceration was obviously overweight.

To the authors' knowledge, no other report in the literature describes an open book pelvic injury from a water slide. When a pelvic injury is suspected, a pelvic splint should be applied and then the patient should have a scoop stretcher placed under their body, with a maximum log roll of $15^{\circ}$ to facilitate positioning. The scoop should then be lifted directly on an ambulance trolley cot, a spinal board or a vacuum mattress for transportation (7).

Lawal et al (8), presented a case of a 72-year old man who was standing with his hips partially abducted and as he bent down to pick-up an item, his legs split uncontrollably. He fell and suffered anterior pelvic pain and an inability to weightbear. The case was the first of its kind in the literature whereby a fall with bilateral hip abduction while doing a split caused a pubic symphysis diastasis. Road traffic accidents/high-energy forces cause the majority of open book injuries. Lawal et al (8), theorized that the mechanism of injury may be secondary to external leg rotation occurring along with leg abduction during the split or was perhaps the result of a fall which led to a significant impact exerted by the patient's bodyweight. The patients in the current case series had violent abduction with external rotation of their lower limbs and would then have a significant impact with the water, due to the high velocity.

There have been very few case reports describing vaginal lacerations resulting from water slide injuries (9-11). The authors are unaware of any reports in the literature of a pelvic injury in combination with a vaginal laceration as a result of a water slide. The vaginal laceration is due to the water being under very high-pressure. It is imperative that emergency room physicians be aware of this potential mechanism of injury in addition to the need for a complete examination under anaesthesia when vaginal bleeding occurs in these situations. This is especially true because it is not uncommon for vaginal lacerations to occur without significant external injury (10). Changes in swimsuit design were a suggested intervention in reducing genital lacerations at water parks.

The patient who suffered a posterior shoulder dislocation also lost control of his limbs once he hit "the bump". Posterior shoulder dislocations are rare injuries accounting for less than $2 \%$ of all shoulder dislocations. It is most commonly caused by an epileptic fit, an electric shock or trauma such as a fall on the outstretched arm (12). It is known that the provocative position is usually forward flexion, adduction and internal rotation, however, the patient stated that once he lost control of his limbs he was unsure of the positions the upper limbs were in as it happened extremely quickly. To the authors' knowledge, this is the first recorded posterior dislocation due to a water slide.

Our teenage patient was the victim of a collision accident which was a bit unusual from the standard collision mechanism which is due to a patron descending the slide too early and colliding with the patron which previously descended. The park in question did have warning signs as to appropriate behaviour, appropriate conduct and the proper starting position in the slide which should be maintained throughout descent. Once the lifeguard at the lower end of the slide yells go, the lifeguard at the entry would allows the next patron to enter. When the lifeguard yelled go, his head was turned away from the patron who was retrieving his goggles, at which point he was hit.

Ball (13) conducted a study aimed at ascertaining the causes of interpersonal collisions on a water slide as well as to determine the adequacy of control systems and potential legal liability via a site investigation. This investigation included, assessment of a traffic light controlled system, closed circuit $\mathrm{TV}$, warning notices, part-time supervision and patron behaviour. It was concluded that although the vast majority of patrons obeyed the safety rules, the risk of injury was still relatively high, making the facility operators vulnerable to a court ruling against them, due to a failure in their duty of care. Cautious patrons may actually increase their friction thus, lowering the exit velocity (4). These findings are particularly interesting in light of the fact that the park in Ball's study had 
significantly superior control systems than the park in this current case series.

As a result of the increase in injuries at the park, increased vigilance in terms of the nurse on duty reporting to transferred health facilities, and various health facilities reporting to the regional health authority, has been put in place. Also, there are increased visitations at the park by representatives of the regional health authority. Park officials are currently trying to determine an appropriate weight limit as well as to get the offending slide assessed by international engineers specializing in water slides to determine a design modification to make the slide safer while maintaining the thrill.

\section{CONCLUSION}

Extremity traumas are very common water park injuries which are mostly minor. Precautions to prevent morbidity and mortality in water parks should decrease the incidence of injuries. With the advent of more advanced, complex rides, awareness must be increased because injuries from atypical mechanisms will occur. Improved surveillance strategies to monitor these injuries are of utmost importance.

\section{REFERENCES}

1. Soyuncu S, Yigit O, Eken C, Bektas F, Akcimen M. Waterpark injuries. Ulus Travma Acil Cerrahi Derg. 2009; 15: 500-4.

2. Malpass CA Jr, Schuman SH, Sobcyk R. Waterslide injuries. Ann Emerg Med 1981; 10: 36.

3. Paulozzi LJ, Mcknight B, Marks SD. A cluster of injuries at a water slide in Washington State. Am J Public Health 1986; 76: 284-5.

4. Blitvich JD, McElroy GK. Waterslide exit velocities, user behaviors and injury prevention. Int J Inj Contr Saf Promot 2007; 141: 54-6.

5. Centres for Disease Control. Injuries at a water slide-Washington. MMWR.1984: 33: 379-7.

6. Davies PD. Water slide aquaplaning injury. BMJ 1990, 300: 1401.

7. Lawal KO, Clayson AD, Charalambous $\mathrm{CP}$. Open book injury secondary to doing the splits. BMJ 2013; doi: 10.1136/bcr-2012-007870

8. Kosola S, Rouche H, Molander P. Vaginal water pressure injury. Duodecim 2010; 126: 181-2.

9. Kunkel NC. Vaginal injury from a water slide in a premenarcheal patient. Ped Emerg Care 1998; 14: 210-11.

10. Niv J, Lessing JB, Hartuv J, Peyser MR. Vaginal injury resulting from sliding down a water chute. Am J Obstet Gynecol 1992; 166: 930-1.

11. Cicak N. Posterior dislocation of the shoulder. J Bone Joint Surg (Br) 2004; 86: 324-32

12. Ball DJ. Some observations on waterslide injuries. Inj Prev 1998; 4: 225 27. 